\title{
Mercantilização e relações de trabalho no ensino superior brasileiro
}

\section{Commodification and labor relations in brazilian higher education}

\author{
Arnaldo França Mazzei Nogueira ${ }^{1}$ \\ Marco Antônio Gonsales de Oliveira²
}

\section{Resumo}

O objetivo deste artigo é analisar as relações de trabalho entre os professores e as Instituições Privadas de Ensino Superior (IPES) no Brasil. A política de expansão da educação superior nacional foi instituída com a Lei de Diretrizes e Bases (LDB) de 1996 e consagrou a mercantilização do ensino superior brasileiro por meio de dois mecanismos combinados: a privatização e a oligopolização. A leitura crítica proposta visa desvendar as contradições do processo de atendimento da demanda de massa por educação mais barata e a degradação do trabalho na educação. Para tanto, foi examinado o referencial bibliográfico voltado para os estudos críticos sobre reestruturação produtiva no âmbito das relações de trabalho do docente, flexibilização das condições de trabalho, e do mercado cada vez mais competitivo. Em um segundo momento, foi realizada uma consulta em fontes documentais disponíveis no Ministério da Educação (MEC) e no Instituto Nacional de Pesquisas Educacionais Anísio Teixeira (INEP), que possibilitou encontrar informações relevantes sobre o setor privado de ensino superior. Para a última etapa desta pesquisa, realizaramse doze entrevistas com professores sindicalizados que vivenciaram processos de fusão na rede particular de ensino superior. Concluiu-se que os dados secundários obtidos por meio das pesquisas do INEP/MEC (2012) e os depoimentos levantados na pesquisa qualitativa apontaram para o mesmo contexto de recente e crescente precarização das relações de trabalho da categoria.

Palavras-chave: Ensino superior. Relações de trabalho. Reestruturação produtiva. LDB.

Professor doutor da PUC-SP (Pontifícia Universidade Católica de São Paulo) - Brasil - E-mail: ajnogueira@pucsp.br

2 Professor mestre da PUC-SP (Pontifícia Universidade Católica de São Paulo) - Brasil - E-mail: professormarcogonsales@gmail.com 


\section{Abstract}

The objective of this paper is to analyze labor relations in private higher education institutions (IPES) in Brazil. The national policy of expanding higher education was institute with the law "LDB 1996" and consecrated the customization of higher education in Brazil through two mechanisms combined: privatization and oligopoly. Critical reading proposal aims to unravel the contradictions of the process of meeting the demand for cheaper mass education and the degradation of work in education. To do so, first looked at the bibliographic references facing critical studies on productive restructuring in relations job of teaching, flexible working conditions and increasingly competitive market. Secondly, there was a query on research from the Ministry of Education and the National Institute for Educational Studies AnísioTeixeira (INEP), which allowed finding relevant information on the private sector of higher education. Thirdly, twelve interviews with unionized professor who experienced mergers in particular higher education companies. The conclusion based in secondary and primary data is a context of recent and growing disqualification of employment relations in private higher education institutions.

Keywords: Higher education. Labor relations. Productiver estructuring. LDB.

\section{Introdução}

O rápido aumento da demanda pela educação e da população escolar no mundo trouxe consigo a crescente participação da iniciativa privada e, consequentemente, um recrutamento em massa de professores na maior parte dos países, nas últimas três décadas.

A transformação da universidade em empresa altera o seu objetivo principal. A sua missão, a essência da sua existência, transforma-se da prestação de serviço educacional de qualidade para a simples obtenção financeira aos seus investidores. Como qualquer empresa privada, todos os outros objetivos são colocados em segundo plano. $O$ docente deixa de ser um ativo para se tornar parte do passivo da instituição. Um custo fixo como qualquer outro, que deve ser sempre contido e, se possível, eliminado.

A política de expansão da educação superior nacional foi instituída com a Lei de Diretrizes e Bases (LDB) de 1996 e consagrou a mercantilização do ensino superior brasileiro por meio de dois 
mecanismos combinados: a privatização e a oligopolização. A leitura crítica proposta visa desvendar as contradições do processo de atendimento da demanda de massa por educação mais barata e a degradação do trabalho na educação.

Nesse contexto, emergiu os seguintes questionamentos: a crescente mercantilização dos serviços de educação do ensino superior precariza as relações e a satisfação no trabalho deste setor?

Para tanto, definiu-se como objetivo investigar as relações de trabalho entre professores e as Instituições Privadas de Ensino Superior (IPES) no capitalismo contemporâneo brasileiro.

Vive-se uma massificação da prestação de serviço de educação de ensino superior por meio da flexibilização das leis de regulação deste setor e, consequentemente, da entrada crescente e competitiva da iniciativa privada, com comprováveis sinais de precarização das relações de trabalho entre professores e as IPES. Para tanto, foram trazidos autores que discutem a problemática da educação superior privatizada e massificada, principalmente no Brasil e na Europa, entre o final do século XX e início do século XXI (ALCADIPANI, 2011; ARONOWITZ, 2000; AUGUSTO, 2005; BEVERUNGEN; DUNNE; SORENSEN; 2008; BOSI, 2008; CHAUÍ, 1999; FREITAS, 2007; FROTA, 2012; MINTO, 2006; OLIVEIRA, 2004; PIMENTA, 2010).

Em um segundo momento, foi realizada uma consulta em fontes documentais disponíveis no Ministério da Educação (MEC) e no Instituto Nacional de Pesquisas Educacionais Anísio Teixeira (INEP), a qual possibilitou encontrar informações relevantes sobre o setor privado de ensino superior.

Para a última etapa deste artigo, foram realizadas doze entrevistas com professores sindicalizados que vivenciaram processos de fusão na rede particular de ensino superior.

A demanda pela a educação superior é um fato, e o acesso tem sido ampliado, principalmente após a LDB de 1996. No entanto, o modelo de expansão via massificação de novas "escolas-empresas" 
amplia e reacende o debate sobre a educação no Brasil. Por um lado, houve êxito do programa em sua capacidade de absorção de tal demanda reprimida. Mas sob quais condições? O recorte deste artigo foi o trabalhador professor, no entanto, a perspectiva dos alunos e de outros trabalhadores envolvidos na educação é fundamental para a ampliação do debate. O que pensam e vivem os trabalhadores e alunos envolvidos no processo de reestruturação do ensino superior?

\section{Mercantilização e relações de trabalho no ensino superior brasileiro}

\subsection{Antecedentes históricos}

As políticas de expansão econômica pós-Segunda Guerra Mundial se esgotaram a partir da década 1970, acelerando a espiral inflacionária, a compressão dos lucros, o congelamento dos investimentos, a crise das finanças públicas e, sobretudo, a impossibilidade de reduzir a taxa de desemprego. Esse cenário levou as empresas a constantes reformulações em seus processos produtivos e sistemas organizacionais na busca pela competitividade. O que, por sua vez, proporcionou uma grande reestruturação produtiva do trabalho baseado nos alicerces da flexibilidade, com vistas a dotar o capital do instrumental necessário para tentar repor os patamares de expansão anteriores.

A reestruturação produtiva acarretou na intensificação do trabalho e ampliou a sua desqualificação e desorganização, tendo um claro objetivo de combater a autonomia e a coesão de setores do operariado, a ponto de reconsiderar o papel do trabalhador coletivo de massa, direitos flexíveis, de modo a dispor dessa força de trabalho em função direta das necessidades do mercado consumidor. A reestruturação produtiva se organizou a partir do mínimo de trabalhadores, ampliando, por meio de horas-extras, os trabalhos temporários, subcontratações e terceirizações, sempre determinados pela demanda do mercado consumidor (ANTUNES, 2008; MENDEL, 1990; MÉSZÁROS, 2009; MORAES, 2014). 
Assim como as empresas, as instituições acadêmicas particulares passam por um processo de reorganização da produção e do trabalho, a reestruturação produtiva. Essa reestruturação tem compatibilizado mudanças institucionais e organizacionais nas relações de produção e de trabalho, associadas às políticas e ideologias neoliberais.

A partir da década de 1990, a América Latina passa pelo aprofundamento das políticas neoliberais, cujos desdobramentos têm sido, entre outros, a reconfiguração da atuação do Estado e do mundo do trabalho, visando garantir a retomada do patamar de rentabilidade do capital. Como consequência dessa reconfiguração, a educação passa por transformações profundas nos seus objetivos, nas suas funções e na sua organização, como tentativa de adequação às demandas a ela apresentadas. A massificação da educação por meio do mercado com baixas regulamentações são visíveis na Europa há mais de um século, e nas últimas duas décadas ocorreu uma intensificação desse processo mediante instituições privadas que atuam como grandes organizações com operações nas principais bolsas de valores do mundo ( $\mathrm{LYNCH}$, 2010).

Vivencia-se uma nova conformação do ideário neoliberal, em que a suposta crise seria resultado das políticas "keynesianas" e do excesso de dinheiro injetado pela intervenção estatal, sendo, portanto, necessário rever, reordenar. São respostas que tentam restaurar taxas de lucro de outrora - reestruturação produtiva, "financeirização" e ideologia neoliberal são os eixos desse processo. Nesse contexto, a educação, como direito e/ou serviço público, perde espaço para a educação privada, como será abordado no decorrer desta pesquisa.

A educação é simplesmente mais um produto de mercado naturalizado na política e nos discursos públicos. Universidades gerenciadas como as empresas são um fenômeno crescente dentro e fora da Europa, e há uma expectativa crescente em vários países de que as IPES contribuam com recursos e capacitação profissional para a sociedade, além de suprirem a grande demanda por educação existente (ARONOWITZ, 2008; BEVERUNGEN, DUNNE, SORENSEN, 
2008; SLAUGHTER, 2001). Criou-se um mercado globalizado cada vez mais oligopolizado e atuante (dependente) nas principais bolsas de valores do mundo, e a última preocupação dessas organizações se tornou a qualidade do principal serviço prestado: a educação. Como ressalta Aronowitz (2000), hoje, presencia-se o fenômeno do capitalismo acadêmico no seu apogeu.

A Educação Superior - ao tornar-se o alvo preferencial da mercantilização da educação e das orientações dos organismos internacionais (Banco Mundial; FMI, etc) na implementação de diretrizes privatizantes -, constitui-se num espaço profícuo de lucratividade a uma fração da burguesia, a burguesia do setor de serviços ao mesmo tempo em que possibilita uma "formação humana limitada", restrita e formatada aos interesses de expansão e continuidade da sociedade capitalista. Isto é, que possibilita a formação de um ser humano integrado à lógica do capital que "... não apenas veste a 'camisa da empresa', mas, acima de tudo, um ser humano que, premido pelas condições materiais, 'veste a camisa do capital'. (TUMOLO, 2003, p. 175)

O crescimento do setor de serviços assume um espaço importante no processo da reprodução capitalista. Dessa forma, observa-se o processo de subordinação da educação aos interesses do mercado, configurando-se em um espaço tanto de disseminação de uma ideologia "do mercado" quanto de uma "formação" da força de trabalho de acordo com as demandas do capital. Um exemplo ilustrativo é o processo de privatizações, que no Brasil teve início da década de 1990 e aprofundouse na gestão do governo de Fernando Henrique Cardoso (1995-2003), estando atualmente ainda fortemente presente nas políticas educacionais brasileiras. A universidade brasileira tem sido objeto desse processo de privatização ainda em curso, o qual tem seguido as diretrizes do Banco Mundial (TUMOLO, 2003).

O Brasil optou pelo crescimento da sua rede de ensino superior a partir da rede privada. Uma consequência prática dessa política começou a ser mais propriamente observada por volta da primeira metade da 
década de 1990, quando a relação de matrículas em cursos presenciais oferecidas por IES privadas e públicas aumentou bastante em favor das primeiras. Se até a década de 1980 cada setor ficava com 50\% das matrículas, no final da década de 1990, a relação foi de $70 \%$ para $30 \%$ em favor das IES privadas. Em 2010, a relação ficou em $74,2 \%$ de matrículas nas redes privadas ante $25,8 \%$ na rede pública.

As políticas neoliberais, mercantilistas e expansionistas na educação superior são refletidas nas práticas das relações de trabalho entre as instituições de ensino e os professores. A política de expansão do ensino superior brasileiro é parte da reforma do Estado implementada no país a partir da década de 1990, chegando aos dias atuais. A reforma consiste, em sua essência, na redefinição do papel do Estado. Por um lado, reafirma o valor do Estado democrático e republicano como o âmbito natural da justiça e como instância estratégica de redistribuição de recursos. Por outro, o Estado, como já mencionado, é desmantelado em função do reforço darwiniano do mercado. As bases da reforma do Estado brasileiro foram estabelecidas em 1995, por meio do Plano Diretor da Reforma do Estado (PDRE), que tem como principais diretrizes a privatização, a terceirização e a publicização (CHAVES, 2010; PIMENTA, 2010; TUMOLO, 2003).

$\mathrm{Na}$ área educacional, a política de focalização se manifesta por meio da priorização dos recursos da União para o atendimento ao ensino fundamental; pela criação de bolsas para os estudantes do ensino superior privado, a exemplo do Programa Universidade para Todos (PROUNI); e pela redução dos investimentos públicos nas instituições públicas de ensino superior, induzindo-as à captação de recursos no mercado capitalista. Assim, o ensino superior deixa de ser direito social e se transforma em mercadoria. A tese é de que o sistema de ensino superior deve se tornar mais diversificado e flexível, em uma expansão com contenção nos gastos públicos. Dando curso a essa política, as instituições privadas de ensino superior foram estimuladas pelos governos a se expandirem por meio da liberalização dos serviços educacionais e da isenção fiscal, em especial da oferta de cursos aligeirados (com mais nome do que conteúdo), voltados apenas para o 
ensino prático e desvinculados da pesquisa (PIMENTA, 2010; TUMOLO, 2003).

No caso dos professores de educação superior, as oportunidades de emprego vêm aumentando, com a expansão das instituições particulares de ensino, em todo o território nacional. A esse aumento numérico da empregabilidade não estão associados os processos de profissionalização, nem inicial e nem continuada, para os docentes universitários, pois as exigências para a docência, nesse nível, se encontram associadas apenas à formação na área específica. Além disso, considerando que, muitas vezes, a atividade docente é assumida como mais uma para a obtenção de renda, e não como profissão de escolha, os próprios docentes não valorizam uma formação profissional (PIMENTA, 2010).

Portanto, é certo que tal crescimento da força de trabalho docente foi (e continua sendo) marcado pela flexibilização dos contratos trabalhistas. Essas possibilidades de contratação precária, abertas por práticas constituídas à margem da lei ou mesmo por modificações na legislação trabalhista, têm feito com que o número de docentes aumente. Assim, quando se torna predominante em número, o trabalho considerado precário e informal tende a se converter em medida para todo tipo de trabalho restante. Esse é o principal fundamento histórico do processo que atravessamos (BOSI, 2007).

Para melhor compreensão do tema, o artigo traz uma breve exposição, com foco na reforma da educação superior, a partir da Lei de Diretrizes e Bases da Educação Nacional (LDB - Lei n. 9.394/1996), e sua relação com a crise do capitalismo e a reforma do Estado.

\subsection{A reforma da educação superior a partir da LDB $\mathbf{n}$. 9.394/1996}

Como já tratado, com a crise do sistema capitalista a partir do final dos anos 1970, o debate sobre o ensino superior ganha força, principalmente por causa das reformas impostas pelo ajuste global do 
capitalismo, que visaram à abertura irrestrita do mercado, por meio de políticas de diminuição do papel do Estado. Com isso, observou-se um movimento de reconfiguração das esferas pública e privada, afetando diretamente a educação e, supostamente, a educação superior. Esse contexto se concretizou nos anos 1990, a partir de um movimento reformista orientado pelos organismos internacionais, como o Fundo Monetário Internacional e o Banco Mundial, em comum acordo com governos neoliberais.

As reformas educacionais exigidas em face aos endividamentos externos são orientadas em razão de financiamento, como fontes de receita para superar o déficit público e estabilizar as economias da região. Defendem a redução dos custos, o aumento da competitividade e a formação de recursos humanos mais produtivos. Um movimento de reforma do Estado capitalista para se adequar ao novo modelo de acumulação flexível.

A reforma do Estado brasileiro pretende modernizar e racionalizar as atividades estatais, redefinidas e distribuídas em setores, podendo ser realizadas por instituições não estatais, na qualidade de prestadoras de serviços. O Estado pode prover tais serviços, mas não os executa diretamente nem executa uma política reguladora dessa prestação. Nesses serviços estão incluídas a educação, a saúde, a cultura e as utilidades públicas, entendidas como "organizações sociais" prestadoras de serviços, que celebram "contratos de gestão" com o Estado. A reforma tem um pressuposto ideológico básico: o mercado é portador de racionalidade sociopolítica e agente principal do bem-estar da República. Esse pressuposto leva a colocar direitos sociais (como a saúde, a educação e a cultura) no setor de serviços definidos pelo mercado. Dessa maneira, a reforma encolhe o espaço público democrático dos direitos e amplia o espaço privado não só ali onde isso seria previsível - nas atividades ligadas à produção econômica -, mas também onde não é admissível - no campo dos direitos sociais conquistados (CHAUÍ, 1999). 
Para Chauí, a reforma flexibiliza leis trabalhistas, como a eliminação do regime único de trabalho e a dedicação exclusiva, substituindo-os por contratos flexíveis, temporários e precários. Além disso, há crescente inclusão do especialista como docente, visando atender às demandas das empresas. Chauí também aponta a deterioração da pesquisa com a criação dos centros autônomos (centros universitários e faculdades), que se abstêm das pesquisas universitárias e apenas oferecem educação de qualidade questionável (CHAUí, 1999).

Essa necessidade da reordenação econômica, política e social do Estado brasileiro ganharia o status de Ministério Federal com a chamada Reforma do Estado, no início dos anos 1990. A reordenação se torna necessária na medida em que é preciso reinstituir a relação Estado-sociedade, perdida com as décadas de crise. Uma espécie de realocação da elite no poder, pelas recentes conquistas sociais. O fim da ditadura, a ascensão dos movimentos sociais, com destaque para as lutas sindicais no ABC paulista e, por último, a Constituição Federal de 1988 significaram um verdadeiro tropeço ante forças históricas do capital (elite), uma vez que instituíram o conflito ao reconhecer os direitos sociais (MINTO, 2006).

A Lei de Diretrizes e Bases da Educação Nacional (LDB), aprovada em 20 de dezembro de 1996, é considerada o marco legal da reforma implantada no país. O Estado assumiu papel destacado no controle e na gestão das políticas educacionais, ao mesmo tempo em que liberalizou a oferta da educação superior pela iniciativa privada.

A partir da LDB de 1996, fica clara a política nacional a ser adotada: o Estado será apenas o regulador e o controlador do serviço, por meio da criação de mecanismos de credenciamento e avaliação. No ensino superior, a LDB promoveu a intensificação do setor privado no mercado, ao admitir a existência e o funcionamento de instituições com fins lucrativos.

A lei anterior - Lei 5.540, de 28 de novembro de 1968, que vigorava para o ensino superior - descrevia, em seu segundo artigo: o ensino superior deveria ser ministrado em universidades e, excepcionalmente, 
em estabelecimentos isolados (BRASIL, 1996). Portanto, a Lei 9.394, de 1996, possibilitou as mudanças para a privatização do ensino superior brasileiro, principalmente quando enfatiza que a educação superior será ministrada em instituições de ensino superior, públicas ou privadas, com variados graus de abrangência ou especialização.

Portanto, a educação superior não seria mais uma exclusividade das universidades. Essa abertura possibilitou às instituições não universitárias usar variados graus de autonomia, em função de sua competência, qualidade ou especificidade, como é o caso do centro universitário. No entanto, apenas o artigo $1^{\circ}$ do Decreto 2.306, de 19 de agosto de 1997, flexibilizou ainda mais a Lei de 1996, segundo o qual tais instituições poderão assumir qualquer das formas admitidas em direito, de natureza civil ou comercial.

Esse novo artigo propiciou a abertura de entidades com fins lucrativos, atraindo empreendedores da iniciativa privada e ampliando a mercantilização do ensino superior. A liberdade civil e comercial, trazida pelo Decreto 2.306, amplia a capacidade privada de investimento nesse setor, por meio do mercado financeiro.

Apenas em 2006, o Decreto 5.773, de 9 de maio de 2006, revogou, em parte, o artigo primeiro do Decreto 2.306, de 1997, e instituía em seu sétimo e nono artigos, supostamente aumentando a regulamentação sobre o setor:

Art. $2^{\circ} \mathrm{O}$ sistema federal de ensino superior compreende as instituições federais de educação superior, as instituições de educação superior criadas e mantidas pela iniciativa privada e os órgãos federais de educação superior... Art. $9^{\circ} \mathrm{A}$ educação superior é livre à iniciativa privada, observadas as normas gerais da educação nacional e mediante autorização e avaliação de qualidade pelo Poder Público. (BRASIL, 2006)

O Decreto de 2006 possibilitou maiores poderes ao poder público, que, por meio do Ministério da Educação, passou a ser autoridade máxima para credenciar e descredenciar as IPES, conforme suas 
metodologias de avaliação. No entanto, o mesmo Decreto 5.773, de 2006, abriu caminho para IPES variadas e inferiores às universidades. Segundo a Portaria Normativa n 40, de 12 de dezembro de 2007, as instituições de educação superior, de acordo com sua organização acadêmica, são classificadas como:

Art. 12. As instituições de educação superior, de acordo com sua organização e respectivas prerrogativas acadêmicas, serão credenciadas como: I - faculdades; II - centros universitários; e III - universidades.

Art. 13. O início do funcionamento de instituição de educação superior é condicionado à edição prévia de ato de credenciamento pelo Ministério da Educação.

$\S 1^{\circ} \mathrm{A}$ instituição será credenciada originalmente como faculdade.

$\S 2^{\circ} \mathrm{O}$ credenciamento como universidade ou centro universitário, com as consequentes prerrogativas de autonomia, depende do credenciamento específico de instituição já credenciada, em funcionamento regular e com padrão satisfatório de qualidade. (BRASIL, 2006; 2007)

O Decreto de 2006 regulamentou e ampliou as possibilidades de modelos de instituições privadas capazes de prestar o serviço de educação superior. Criou o modelo chamado de centro universitário, uma deterioração da universidade. Como mostrado a seguir, o Decreto enfatiza que a principal diferença entre a universidade e o centro universitário é o professor. Assim, o centro universitário contrata professores com titulações inferiores e contratos de trabalho flexibilizados em relação aos professores universitários.

Como demonstra o Decreto, das três principais diferenças entre a universidade e o centro universitário, duas são relacionadas diretamente aos professores:

Os centros universitários são instituições de ensino superior pluricurriculares que se caracterizam pela excelência do ensino oferecido, pela qualificação do seu corpo docente e pelas condições de trabalho acadêmico 
oferecidas à comunidade escolar. São requisitos de atendimento por essas instituições: I - um quinto do corpo docente em regime de tempo integral; e II - um terço do corpo docente, pelo menos, com titulação acadêmica de mestrado ou doutorado, conforme Decreto $n^{\circ} 5.786$, de 24 de maio de 2006.

As universidades são instituições pluricurriculares de formação dos quadros profissionais de nível superior, de pesquisa, de extensão e de domínio e cultivo do saber humano, que se caracterizam por: I - produção intelectual institucionalizada mediante o estudo sistemático de temas e problemas mais relevantes tanto do ponto de vista científico e cultural quanto regional e nacional; II um terço do corpo docente, pelo menos, com titulação acadêmica de mestrado ou doutorado; III - um terço do corpo docente em regime de tempo integral, conforme Lei 9.394, de 20 de dezembro de 1996. (BRASIL, 2012)

O tempo integral normalmente solicita do docente as três funções características da universidade: ensino, pesquisa e extensão. Podese facilmente constatar que, nessas condições de trabalho, o tempo integral torna mais viável a efetivação das três funções. Nos casos dos professores horistas, a maioria no ensino superior brasileiro particular, o papel do docente centra-se na hora-aula, pois é esse o tempo para o qual ele é pago. Como o valor obtido por esse trabalho costuma ser insuficiente para a sobrevivência, o professor obriga-se a ampliar os turnos e a trabalhar em mais de uma instituição para obter uma renda mensal básica. Assim, fica com todo o seu tempo disponível para deslocamento e sala de aula (PIMENTA, 2010).

Nos últimos vinte anos, as escolas de ensino superior públicas têm sofrido com a austeridade em seus recursos, o que as levou a buscar soluções alternativas no mercado, como parcerias com as IPES. Esse mesmo período tem experimentado um enorme crescimento das escolas que visam ao lucro, o que tem acarretado um aumento da concorrência para as organizações existentes. A LDB abriu o mercado para a exploração de serviços de ensino por instituições privadas, 
o que proporcionou uma grande diversidade de organizações, com consequente aumento da competição no ambiente. Essas novas instituições têm o objetivo de servir à demanda reprimida e não atendida pelas escolas existentes (FREITAS; BANDEIRA-DE-MELO, 2013).

Alcadipani (2011), mais especificamente na área da gestão, fala sobre a educação fast-food. Vende-se ensino minimizando inputs e maximizam-se outputs (diplomados). Cursos enlatados, professores mal remunerados e livros-texto de baixa qualidade a rodo.

Os fastfoods do ensino "enchem a burra" com o dinheiro alheio vendendo diploma à prestação. Impera a lógica de mercado mais rasteira e mais nefasta possível. A maioria de nós assiste a isso sem muito falar. O processo se naturalizou. $\mathrm{Na}$ verdade, não se trata de fordismo aplicado à educação, pois, se fizesse carros como estas escolas formam os alunos, a Ford jamais teria sido uma empresa de sucesso, seus carros sequer andariam. A quem interessam tais cursos? (ALCADIPANI, 2011, p. 1174)

Para Frota e Teodósio (2012), valores como autonomia, participação e democratização foram assimilados e reinterpretados, substantivados em procedimentos normativos que modificaram 0 trabalho escolar. O trabalho pedagógico foi reestruturado, dando lugar a uma nova organização escolar, e tais transformações, sem as adequações necessárias, parecem implicar processos de precarização do trabalho docente.

Freitas (2007) fala sobre as tarefas "extraclasse", ampliadas nesse novo contexto através do desenvolvimento da tecnologia da informação (TI). Agora, o professor deve ter conhecimentos tecnológicos mínimos para preparar seu material didático, usando novas ferramentas sem preparação adequada para tanto, enviar seus artigos de sistemas de informática, manter seus cadastros com diversas entidades, acompanhar financiamentos junto a órgãos de fomento, acompanhar e avaliar o trabalho de seus alunos, validar trabalhos para revistas e congressos. Além disso, as novas IPES não possibilitam apoio administrativo. 
Professores são destinados a essas tarefas. Uma parte significativa da carga de trabalho é realizada em casa, à noite ou aos finais de semana, em grande parte sem terem essas horas registradas em seus holerites.

Bosi (2007) fala sobre uma percepção generalizada de professores universitários que têm acusado o aumento, a intensificação e a desvalorização de seu trabalho. O autor exemplifica essa situação com a cobrança por produtividade que os órgãos de fomento fazem e o aumento da carga horária imposta aos professores. Outra incerteza de que sofrem os atuais professores refere-se à instabilidade da carga horária. As matrículas tardam a preencher as classes das IPES, e os professores são notificados de sua carga horária apenas poucos dias antes do início das aulas. Portanto, cabe a estes manter seus cadastros em diversas instituições, para tentar ter alguma estabilidade. Grande parte dos professores atua em duas ou três instituições e muitos ainda prestam algum serviço (por fora) para complementar a sua renda. $O$ exercício da docência, no capitalismo contemporâneo, e principalmente nas IPES, dificulta a autorrealização e a satisfação, o sentimento de desenvolvimento e a evolução pessoal (TOLFO; PICCININI, 2007). A própria característica flexível dessas ocupações profissionais dificulta a identificação e o compromisso entre o profissional e a organização. Como planejar uma carreira estando em duas, três ou quatro instituições?

\subsection{A mercantilização do ensino superior e a função do professor}

As relações de trabalho sofreram alterações a partir da política de expansão da educação superior nacional, instituída com a Lei de Diretrizes e Bases de 1996. Essa lei abriu caminho para o predomínio da privatização do ensino superior brasileiro. Em sequência, ocorreu forte oligopolização, com a criação de redes de empresas, por meio da compra e fusão de instituições de ensino superior privadas do país, seja por empresas nacionais ou internacionais, e pela abertura de capitais destas nas bolsas de valores. Entende-se esse processo como uma mercantilização do ensino superior, submetendo os professores a reduzirem sua força de 
trabalho à forma abstrata do valor de troca como mercadoria. Em outras palavras, a força de trabalho do professor passa a ser fundamental como geradora da mais-valia.

Assim, vê-se reduzida a sua dimensão qualitativa como valor de uso do trabalho em favor da dimensão quantitativa como ativo contábil e custo, como em qualquer outra organização privada e obstinada pelo lucro. Com a expansão do ensino privado, aumenta o emprego da força de trabalho. Seria um fator favorável, não fossem as condições precárias da maioria desses trabalhadores do ensino. Isso traz um questionamento do modelo adotado entre a eficácia do negócio capitalista da educação e a efetividade/legitimidade do ensino de qualidade.

Os últimos anos têm trazido mudanças significativas para os trabalhadores docentes das IPES nacionais. São reformas que atuam não só no nível da instituição, mas em todo o sistema, repercutindo em mudanças profundas na natureza do trabalho do docente. São trazidas para debates as discussões sobre os processos de flexibilização e precarização das relações de trabalho entre os professores e as IPES. A intensificação da participação da iniciativa privada na oferta dessa modalidade de educação aprofunda a relevância do tema (AUGUSTO, 2005).

As recentes mudanças no mundo do trabalho (reestruturação produtiva, flexibilização da legislação trabalhista, precarização do trabalho etc.) tornam-se, cada vez mais, objeto de debates nas universidades. No caso do trabalho docente, as discussões têm esclarecido sobre as diversas dinâmicas de precarização vivenciadas na docência do ensino fundamental, médio e superior (OLIVEIRA, 2004).

O ensino superior no Brasil vive um momento ímpar na história da educação superior mundial. Os negócios de fusão e aquisição já envolveram 182 instituições desde março de 2007, quando foi realizada, na bolsa de valores, a primeira oferta pública oficial pela Anhanguera Educacional. A previsão de especialistas de mercado é de que o processo de compra e venda se mantenha por mais alguns anos, o que vai dar uma nova cara para o setor (BRAGA et al., 2011). 
A abertura do capital das principais IPES brasileiras ao mercado de ações, e a sua consequente valorização, possibilitam o aumento de seu capital, a compra de outras instituições menores espalhadas no país e, com isso, a formação de grandes grupos empresariais, também denominados "redes", em processo de oligopolização de mercado. As concepções anteriormente resumidas entre o paradigma moderno e pós-moderno vêm acarretando importantes mudanças no professorado. Para Morosini (2008), a última década registrou características de deterioração na categoria de professor, principalmente devido à massificação, à diminuição do suporte financeiro público e de fundos de pesquisas. As políticas neoliberais, mercantilistas e expansionistas na educação superior são refletidas nas práticas das relações de trabalho entre as instituições de ensino e os professores.

Diante da importância da função do professor quando se fala em educação de qualidade, aspectos fundamentais para a atividade do docente, como formação, duração da jornada de trabalho, remuneração e estrutura da carreira (VIEIRA, 2003) deveriam receber o tratamento adequado na pauta das políticas educacionais. No entanto, observase que, com a intensificação da iniciativa privada no ensino superior, as relações trabalhistas entre docentes e IPES deterioram-se. Mas em quais aspectos?

As relações trabalhistas são fundamentais para o exercício de qualquer profissão, principalmente em uma sociedade sob a lógica capitalista, e não é diferente quando se trata da docência no contexto do sistema educacional brasileiro atual. Nesse sentido, é fundamental ressaltar que por trás da discussão das relações de trabalho está a remuneração como fator relevante para a garantia da qualidade em qualquer profissão. Valorizar o docente é atrair bons profissionais e, consequentemente, elevar a qualidade do serviço prestado.

As relações trabalhistas entre as IPES e os professores sofreram alterações a partir da política de expansão da educação superior nacional pela rede particular, instituídas após a Lei de Diretrizes e Bases de 1996? Quais alterações? 
O processo de inclusão de massa no ensino superior pelas redes particulares, as IPES, tem contribuído para a deterioração das relações de trabalho com os professores. A recente entrada das maiores IPES brasileiras no mercado financeiro as afastam ainda mais do compromisso central de uma instituição de ensino superior, e as levam para o objetivo comum de toda empresa: o retorno financeiro aos seus investidores, a obstinação do lucro por si só.

O Censo da Educação Superior 2010 - Panorama Nacional do Ensino Superior, produzido pelo Ministério da Educação (MEC) em parceria com o Instituto Nacional de Estudos e Pesquisas Educacionais Anísio Teixeira (INEP), traz dados que enfatizam o processo de mercantilização do ensino superior brasileiro na primeira década do século $X X I$.

\subsection{Censo da Educação Superior 2010 - Panorama Nacional do Ensino Superior}

O total de instituições em 2001 era de 1.391. Em 2010, chegou a 2.378. O crescimento foi de $74 \%$ em 10 anos. As IES públicas cresceram menos, 53\%. Já as IPES correspondiam a $86,8 \%$ das IES no Brasil em 2001 e, em 2010, representavam 88,3\%, confirmando a ascensão no ensino superior das IPES na última década. As IES públicas diminuíram sua participação na rede nacional de ensino superior de 13,2\%, em 2001, para apenas 11,7\% em 2010 (INEP, 2012).

Seguindo a mesma tendência de crescimento, o número de matrículas nas IPES alcançou os 74,2\% em 2010. Em 2001, esse número era de $68,9 \%$, ou seja, houve um crescimento de $5,3 \%$. As IES públicas eram responsáveis, em 2001 , por $31,1 \%$ das matrículas nacionais. Em 2010, o número foi de 25,8\% (INEP, 2012).

Em 2011, havia 378.257 docentes no ensino superior brasileiro. Na rede particular, eram 227.442, o que representava $60 \%$ desse total. Segundo o censo, as IPES aumentaram o número de professores mestres e doutores em relação aos professores com formação até especialização 
(graduação ou especialização). As IES públicas contavam, em 2010, com $78,8 \%$ dos seus docentes com títulos de mestres ou doutores $(28,9 \%$ mestres e $49,9 \%$ doutores). Já as IPES contavam com apenas 58,5\% dos docentes com titulação de mestres ou doutores $(43,1 \%$ mestres e 15,4\% doutores) (INEP, 2012).

Houve uma pequena elevação das funções dos docentes com doutorado nas instituições privadas, mas esse percentual ainda se mostra bastante reduzido comparativamente ao observado nas instituições públicas. Verificou-se uma correspondência de três funções docentes com doutorado nas IES públicas para cada função docente com essa titulação nas IPES (INEP, 2012).

Nas IPES, existe a prevalência do regime de trabalho de horistas, ainda que esses tenham diminuído de $55,8 \%$, em 2002 , para $48,0 \%$ em 2010. Os regimes integral e parcial aumentaram seus percentuais de participação, sobretudo de 2008 para 2010. No ano de 2010, 24\% dos regimes de trabalho eram em tempo integral, e 28,0\% em tempo parcial (INEP, 2012).

Em comparação com a categoria pública, o regime de trabalho de tempo integral predominou na primeira década deste século. Nas IES públicas, pode-se observar que são crescentes os percentuais relativos a tempo integral, ao longo do período pesquisado, passando a representar $80,2 \%$ em 2010. O regime de tempo parcial, por sua vez, passou de $18,5 \%$, em 2002, para 12,9\% em 2010. Residualmente, o percentual de horistas representou 6,8\% em 2010. As IPES em 2010 possuíam apenas $24 \%$ dos seus docentes em regime de tempo integral, uma diferença alarmante ao comparamos com o mesmo tipo de contrato de trabalho com as IES públicas, que têm $80,2 \%$ dos professores em regime integral (INEP, 2012).

O Plano Nacional de Educação desenhado pelo MEC estabelece como meta a matrícula de 33\% da população com idade entre 18 e 24 anos no ensino superior. Apenas $14,6 \%$ desse contingente, estimado em cerca de 20 milhões de pessoas, está matriculado em faculdades e universidades (PNAD, 2011). Portanto, o mercado brasileiro torna-se 
interessante para investidores por dois motivos: manutenção e ampliação da política de expansão do ensino superior pela iniciativa privada, um enorme mercado a ser explorado.

No entanto, no que concerne aos professores, o trabalho ainda se realiza, em sua maioria, sob a forma de emprego, apesar de já se anunciarem novas formas, como o trabalho autônomo e terceirizado. Há outras modalidades, como a monitoria, que substituem o trabalho do professor pelo aluno, ou mesmo a utilização do ensino a distância como mais uma alternativa de redução de custo com mão de obra especializada.

\subsection{A formação de oligopólios no ensino superior privado}

Para Braga et al. (2011), o mercado do ensino superior no Brasil vive um processo de reestruturação e consequente oligopolização. Os negócios de fusão e aquisição já envolveram 182 instituições desde março de 2007, quando foi realizada na bolsa de valores a primeira oferta pública oficial pela Anhanguera Educacional.

A abertura do capital e a valorização dessas empresas possibilitam o aumento de seu capital, a compra de outras instituições menores espalhadas no país e, com isso, a formação de grandes grupos empresariais, também denominados "redes". Como passam a adquirir materiais e equipamentos em grandes quantidades, conseguem reduzir seus custos operacionais e aumentar suas margens de lucro, possibilitando a diminuição dos valores das mensalidades. Com o crescimento desses grandes grupos empresariais e a redução das mensalidades cobradas por eles, as pequenas faculdades não conseguem se manter no mercado e acabam sendo absorvidas. A maioria das instituições adquiridas por essas grandes empresas é de porte pequeno ou médio, estando localizadas no interior do país e endividadas (CHAVES, 2010).

Observa-se um processo intenso de concentração, ou também, um processo de oligopolização. Ou seja, o número de fornecedores tende a 
se concentrar ainda mais nos próximos anos, e uma fatia significativa do mercado tende a ficar com os maiores grupos. Mantidas as condições atuais de sustentação exclusivamente por mensalidades, poucos serão os que conseguirão ocupar nichos específicos do mercado sem serem acossados pelas instituições maiores.

\subsection{Professores: uma ilustração}

Foram doze entrevistados, docentes de IPES, todos sindicalizados e que recentemente vivenciaram a venda da instituição onde trabalhavam para uma IPES de grande porte, ou vivenciaram um momento de fusão na instituição. Foram realizadas entrevistas presenciais e individuais a partir de técnicas qualitativas com questionários semiestruturados. As entrevistas foram realizadas ao longo do primeiro semestre de 2013, no Sindicato dos Professores de São Paulo, o SINPRO-SP. Como já mencionado, todos os entrevistados são sindicalizados, portanto, cabe ressaltar que são professores que lutam pelos seus direitos e pela melhoria do trabalho em sua categoria. Possuem relatos críticos, reconhecem o crescimento do setor como benéfico para toda a categoria, mas não concordam com a forma mercantil que predomina nas IPES nacionais e responsabilizam a falta de regulamentação desse mercado como essencial para um desenvolvimento sustentável.

Os docentes entrevistados trouxeram importantes contribuições para este artigo, o qual objetivou traçar a realidade das relações de trabalho entre professores e as IPES brasileiras, deterioradas nas últimas décadas pelo processo de massificação e mercantilização do setor. São professores que trabalham na capital e na Grande São Paulo, o que não diminui a similaridade com a realidade do cenário nacional, principalmente porque o Plano de Diretrizes e Bases do Ensino Superior, a LDB de 1996, é federal, portanto, traz consigo causas e efeitos semelhantes em todo o país.

Os professores atuam em duas ou três instituições. Há nos relatos contratos de prestação de serviço feitos frequentemente por emissão 
de nota fiscal, com pagamento apenas dos impostos e abdicação dos direitos trabalhistas.

Trabalho quase 50 horas por semana em 3 faculdades [...], sou professora há apenas 3 anos, sou apenas especialista e ainda não tenho carteira assinada por nenhuma delas. (ENTREVISTADO 1)

Sou registrado, sempre fui, mas ser registrado em diferentes instituições é complicado. (ENTREVISTADO 2)

Os profissionais afirmam que perdem muito tempo para se deslocarem entre as IPES, principalmente em uma metrópole como São Paulo. Também contestam a falta de estabilidade por serem horistas. Em todos os semestres há o aguardo do preenchimento de matrículas para, de última hora, saberem o quanto, e se irão ou não lecionar.

É impossível planejar, fazer uma agenda financeira. Não sabemos quantas horas iremos lecionar, nos passam o planejamento a pouco dias do início das aulas, e muitas vezes só depois. Esperam as matrículas e as transferências de alunos para preencher classes. Há pouco tempo comecei a lecionar em uma classe que foi mesclada com outra (por falta de aluno) e, portanto, tive o meu trabalho interrompido no meio do semestre letivo. (ENTREVISTADO 1)

Meu sonho seria atuar em apenas uma instituição. Ser horista é o nosso maior problema. Quando vem o leão (imposto de renda), as pernas até tremem. Como recebemos picado em diversas faculdades, o nosso imposto de renda não é retido na fonte. (ENTREVISTADO 5)

Os entrevistados que vivenciaram algum processo de venda da IPES em que atuavam citam que os contratos foram desfeitos e novas propostas de remuneração foram oferecidas, sem preocupação com as consequências legais trabalhistas.

Poucos processam e muitos aceitam em nome do 
emprego. Como poucos colegas são registrados, poucos são sindicalizados, o que dificulta ainda mais a nossa luta por melhores salários e condições de trabalho. (ENTREVISTADO 8)

A remuneração, que já é ruim, ficou ainda pior. O valor de hora-aula passou, no meu caso, de 28 reais por hora para apenas 18 reais. Isso agora, que compraram a instituição onde eu trabalhava em 2012 [...]. Nos anos noventa, meu pai, professor universitário também, chegava a receber 80 reais por hora, no começo do Plano Real. Outro problema é que não temos nenhum tipo de benefício. Horista dificilmente obtém a carga horária necessária, em uma empresa, para ter um plano de saúde ou pelo menos o almoço ou jantar pago. (ENTREVISTADO 4)

Após o processo de venda da instituição, os extras dos professores coordenadores foram cortados. Deixei de ser coordenador e ainda o meu salário foi reduzido em 25\%. Foi tudo tão rápido. No recesso de 2013, ao voltarmos para o trabalho, tudo tinha sido resolvido sem nos notificar para planejarmos o nosso futuro (venda da instituição). (ENTREVISTADO 7)

Hoje atuo em três instituições para poder pagar o ensino médio das minhas filhas. Sou professor do ensino superior, mas leciono no ensino médio apenas para elas poderem cursar gratuitamente nesta instituição [...]. Trabalho 48 horas por semana, aos sábados inclusive. Preciso estudar, fazer doutorado, para procurar alguma instituição federal ou estadual, mas falta tempo e dinheiro [...]. Não recebemos benefícios; isso não existe em nossa categoria. O nosso benefício, quando muito, é o cafezinho do intervalo. (ENTREVISTADO 11)

Os professores tornam-se reféns dos processos de venda e fusão, já que dificilmente são informados pelas diretorias responsáveis. Nesse mercado, as contratações e demissões ocorrem a cada semestre, devido ao calendário do ensino superior. Portanto, os profissionais não têm escolha quando se deparam com um processo de venda e fusão entre um semestre e outro. As instituições não dão alternativas para 
os professores se planejarem ou se organizarem no trabalho e na vida pessoal.

O plano de carreira que sempre foi enfatizado pela antiga diretoria mudou. As novas regras ainda não foram apresentadas. [...] Os planos de carreira são sempre um mistério nas instituições particulares. Poucos sabem e poucos de fato utilizam. A maioria dos professores não pesquisa por falta de tempo e conhecimento. (ENTREVISTADO 9)

Outros assuntos abordados valem ser ressaltados. Segundo os professores entrevistados, as IPES, em sua maioria, se utilizam de atividades de EAD (ensino a distância) para serem contabilizadas como aula na grade curricular. Um engenhoso mecanismo, o qual pode ser chamado de "aula fictícia", regulamentado e aprovado pelo MEC por meio da Portaria $n^{\circ} 4.059$, de 10 de dezembro de 2004, que autoriza a inclusão de disciplinas não presenciais em cursos superiores reconhecidos.

$\S 1^{\circ}$ Para fins desta Portaria, caracteriza-se a modalidade semipresencial como quaisquer atividades didáticas, módulos ou unidades de ensino-aprendizagem centrados na autoaprendizagem e com a mediação de recursos didáticos organizados em diferentes suportes de informação que utilizem tecnologias de comunicação remota.

$\S 2^{\circ}$ Poderão ser ofertadas as disciplinas referidas no caput, integral ou parcialmente, desde que esta oferta não ultrapasse $20 \%$ (vinte por cento) da carga horária total do curso. (BRASIL, 2004)

Com essa nova portaria, algumas IPES fazem no período noturno a mágica de dois turnos de duas horas cada, e muitas ainda abdicam das aulas de sexta-feira. Também, como relatam os professores, a eles são ofertados cargos de "conteudistas" e monitoria em EAD, com salários inferiores e sem direitos a transporte e refeição. 


\section{Considerações finais}

O objetivo principal deste artigo foi analisar as relações de trabalho nas Instituições Privadas de Ensino Superior (IPES). A política de expansão da educação superior nacional foi instituída com a Lei de Diretrizes e Bases de 1996. A lei consagrou a mercantilização do ensino brasileiro por meio de dois mecanismos combinados: a privatização e a oligopolização.

A privatização significou a expansão da rede privada de ensino, que passou a ocupar um papel relevante no atendimento da demanda e na abertura de vagas, muitas delas financiadas pelo poder público, por programas e bolsas de estudos, como o Fies e o Prouni.

A oligopolização surgiu com a criação de redes de empresas, nascidas por compra e fusão de instituições privadas de ensino superior, cujos exemplos mais relevantes são o grupo Kroton e a Anhanguera, que recentemente anunciaram a fusão. As relações de trabalho são afetadas por esse processo e tendem à forte precarização das condições e do salário. Por consequência, as condições de ensino, pesquisa e extensão também ficam comprometidas.

Entende-se esse processo como mercantilização do ensino superior, que submete os professores a reduzirem sua força de trabalho à forma abstrata do valor de troca como mercadoria. Em outras palavras, a força de trabalho do professor passa a ser fundamental como geradora da mais-valia. Assim, vê-se reduzida a sua dimensão qualitativa como valor de uso do trabalho em favor da dimensão quantitativa como ativo contábil e custo, como em qualquer outra organização privada e obstinada pelo lucro.

Com a expansão do ensino privado, aumenta o emprego da força de trabalho. Seria um fator favorável, não fossem as condições precárias da maioria desses trabalhadores do ensino. Isso traz um questionamento do modelo adotado entre a eficácia do negócio capitalista da educação e a efetividade/legitimidade do ensino de qualidade. As políticas neoliberais, mercantilistas e expansionistas na educação superior são 
refletidas nas práticas das relações de trabalho entre e as instituições de ensino e os professores.

As relações trabalhistas entre as IPES e os professores sofreram alterações a partir da política de expansão da educação superior nacional pela rede particular, instituídas após a Lei de Diretrizes e Bases de 1996? Quais alterações?

O Decreto 5.773, de 2006, complementar à LDB de 1996, abriu caminho para IPES variadas, pois ampliaram-se as possibilidades de modelos de instituições privadas. Além disso, criou o modelo chamado de centro universitário, uma deterioração da universidade. O decreto enfatiza que a principal diferença entre a universidade e o centro universitário é a formação do professor e o seu regime de trabalho. Portanto, o centro universitário seleciona professores com titulações inferiores e contratos de trabalho flexibilizados em relação aos professores universitários.

Como demonstrado no censo da educação superior realizado pelo INEP, há um hiato entre os modelos de contratação de professores da rede pública e da rede particular.

Nas IPES, verificou-se a prevalência do regime de trabalho de horistas, ainda que este tenha diminuído de 55,8\%, em 2002, para 48,0\% em 2010. As IPES, em 2010, possuíam apenas $24 \%$ dos seus docentes em regime de tempo integral, uma diferença alarmante ao comparamos com o mesmo tipo de contrato de trabalho com as IES públicas, que têm $80,2 \%$ dos professores em regime integral (INEP, 2012).

As consequências desse modelo foram trazidas nas vozes dos professores da rede particular. São reclamações no âmbito trabalhista, como salário baixo, ausência quase total dos benefícios, excesso da jornada de trabalho, falta de um plano de carreira e profissionalismo na gestão de pessoas. A questão da saúde e do assédio moral ao trabalhador do ensino superior são temas que demandam por novos estudos e debates mais robustos. São raras as pesquisas sobre o trabalhador professor no capitalismo contemporâneo (CAVALHEIRO; TOLFO, 2011) 
As relações trabalhistas são fundamentais para o exercício de qualquer profissão, principalmente em uma sociedade sob a lógica capitalista, e não é diferente quando se trata da docência no contexto do sistema educacional brasileiro atual. Nesse sentido, é fundamental ressaltar que por trás da discussão das relações de trabalho está a remuneração, como fator relevante para a garantia da qualidade em qualquer profissão. Valorizar o docente é atrair bons profissionais e, consequentemente, elevar a qualidade do serviço prestado.

\section{REFERÊNCIAS}

ALCADIPANI, R. Resistir ao produtivismo: uma ode à perturbação Acadêmica. Cad. EBAPE.BR, Rio de Janeiro, v. 9, n. 4, Dez. 2011.

ARONOWITZ, S. The Knowledge Factory: dismantling the corporate university and creating true higher learning. Boston: Beacon Press, 2000.

ANTUNES, R. Adeus ao trabalho? ensaio sobre as metamorfoses e centralidade do mundo do trabalho. 13ª ed. São Paulo: Cortez, 2008.

AUGUSTO, M. H. O. G. As reformas educacionais e o 'choque de gestão': a precarização do trabalho docente. In: REUNIÃO ANUAL DA ASSOCIAÇÃO NACIONAL DE PÓS-GRADUAÇÃO E PESQUISA EM EDUCAÇÃO DA ANPED, 28., 2005, Caxambú. Anais... Caxambú: ANPED, 2005, p. 1-16.

BEVERUNGEN, A.; DUNNE, S.; SORENSEN, B. M. University, failed. Ephemera: theory \& politics in organization, Lunerburg , v. 8, n. 3, p. 232-237, Aug, 2008.

BOSI, A. P.. A precarização do trabalho do docente nas instituições de ensino superior do Brasil. Nesses últimos 25 anos. Educ. Soc., Campinas, v. 28, n. 101, p. 1503-1523, set./dez. 2007.

BRASIL. Lei 9.394 de 20 de dezembro de 1996. Regulamenta o $\S 1^{\circ}$ do art. 7, que estabelece as diretrizes e bases da educação nacional. 
Diário Oficial [da] República Federativa do Brasil, Poder Executivo, Brasília, DF, 20 dezembro de 1996.

BRASIL. Lei 9.394 de 20 de dezembro de 1996. Regulamenta o $\S$ 81 e no art. $1^{\circ}$ do Decreto $N^{\circ} 2.494$, de 10 de fevereiro de 1998, que estabelece as diretrizes e bases da educação nacional. Diário Oficial [da] República Federativa do Brasil, Poder Executivo, Brasília, DF, 10 dezembro de 2004.

BRASIL. Decreto 5.773 de 09 de maio de 2006. Regulamenta através do art. 12 e 13, Dispõe sobre o exercício das funções de regulação, supervisão e avaliação de instituições de educação superior e cursos superiores de graduação e sequenciais no sistema federal de ensino. Diário Oficial [da] República Federativa do Brasil, Poder Executivo, Brasília, DF, 09 de maio de 2006.

CAVALHEIRO, G.; TOLFO, S. R. Trabalho e depressão: um estudo com profissionais afastados do ambiente laboral. Psico-USF, Itatiba , v. 16, n. 2, p. 241-249, May/Aug. 2011.

CHAUÍ, M. A universidade operacional. Avaliação: Revista da Avaliação da Educação Superior, Campinas, v. 4, n. 3, p. 3-8, Suplemento 01, 1999.

RISTOFF , D.; SEVEGNANI, P. Docência na educação superior: Brasília, $1^{\circ}$ e 2 de dezembro de 2005. Brasília: Instituto Nacional de Estudos e Pesquisas Educacionais Anísio Teixeira, 2006. 329p. (Coleção Educação Superior em Debate; v. 5)

FREITAS, M. E. A carne e os ossos do ofício acadêmico. O \& S, Bahia, v.14, n.42, Jul/Set, p.187-191, 2007.

FREITAS, A; Bandeira-De-Mello, R. Uma Grounded Theory Para a Ação Gerencial No Processo De Implementação Do E-Learning nas Escolas de Negócios do Brasil. Revista de Administração e Contabilidade da Unisinos, Porto Alegre, v. 10, n. 2, p. 100-116, Abril/ Junho, 2013. 
FROTA, G. B.; Teodósio, A. S. S. Profissão Docente, Profissão Decente?: Estratégias de professores frente ao sofrimento no trabalho em um ambiente de inovação pedagógica. In: ENANPAD, XXXVI, 2012, Rio de Janeiro. Anais... Rio de Janeiro: ENANPAD, 2012. p. 0116

INSTITUTO BRASILEIRO DE GEOGRAFIA E ESTATÍSTICA. Síntese de indicadores sociais: uma análise das condições de vida da população brasileira. Rio de Janeiro: Ministério do Planejamento e Gestão, 2012

INSTITUTO NACIONAL DE ESTUDOS E PESQUISAS EDUCACIONAIS ANÍSIO TEIXEIRA. Censo da educação superior 2010. Brasília: Instituto Nacional de Estudos e Pesquisas Educacionais Anísio Teixeira, 2012.

MANDEL, E. A crise do capital: os fatos e a sua interpretação marxista. São Paulo: Ensaio; Campinas: Editora da Unicamp, 1990.

MÉSZÁROS, I. A crise estrutural do capital. São Paulo: Bomtempo, 2009

MINTO, L. W. As reformas do Ensino Superior no Brasil: o público e o privado em questão. São Paulo: Autores Associados, 2006.

MORAES, L. C. Godoi. Pulverização de capital e intensificação do trabalho: o caso da EMBRAER. 2013. 353 f. Tese (Doutorado em Sociologia ) - Universidade de Campinas, Campinas, 2013.

OLIVEIRA, D. A. A reestruturação do trabalho docente: precarização e flexibilização. Campinas: Educação \& Sociedade, v. 25, n. 89, p. 1127-1144, set./dez. 2004.

PIMENTA, S. G.; ANASTASIOU, L.das G. C.; CAVALLET, V. J. Docência no ensino superior: construindo caminhos. In: BARBOSA, R. L. L. Formação de educadores: desafios e perspectivas. São Paulo: UNESP, 2003. p. 267-278. 
SENO, J. P.; KAPPEL, L. B.; VALADÃO JÚNIOR, V. M. As percepções do professor universitário da área de gestão acerca das mudanças na educação superior: uma pesquisa com profissionais de Instituições de Ensino Privadas do Triângulo Mineiro. Gestão \& Regionalidade, São Caetano do Sul, v. 30, n. 88, p. 49-61, jan-abr, 2014.

SLAUGHTER, S.; LESLIE, L.L. Expanding and elaborating the concept of academic capitalism. Organization, Cambridge, v. 8, n. 2, p.154161, May. 2001.

TOLFO, S. R.; PICCININI, V. Sentidos e significados do trabalho: explorando conceitos, variáveis e estudos empíricos brasileiros.

Psicologia e Sociedade, Florianópolis, v. 19, Edição Especial 1, p.3846, 2007.

TUMOLO, P. S. Da contestação à conformação: a formação sindical da cut e a reestruturação capitalista. São Paulo: Unicamp, 2003. 175p.. 